\title{
Biosorption of ibuprofen using functionalized bean husks
}

\author{
Olugbenga Solomon Bello ${ }^{\mathrm{a}, \mathrm{b}, *}$, Oluwakemi Christiana Alao ${ }^{\mathrm{a}}$, Temitope Chris Alagbada ${ }^{\mathrm{a}}$, \\ Abimbola Modupe Olatunde ${ }^{c}$
}

${ }^{a}$ Department of Pure and Applied Chemistry, Ladoke Akintola University of Technology, P.M.B. 4000, Ogbomoso, Oyo State, Nigeria

${ }^{\mathrm{b}}$ Department of Physical Sciences, Industrial Chemistry Programme, Landmark University, Omu-Aran, Nigeria

${ }^{\mathrm{c}}$ Department of Chemistry, University of Ibadan, Oyo State, Nigeria

\section{A R T I C L E I N F O}

\section{Keywords:}

Ibuprofen

Bean husks

Equilibrium isotherms

Activated carbon

\begin{abstract}
A B S T R A C T
The ability of bean husk, an agricultural waste, as a promising adsorbent for sequestering Ibuprofen from aqueous solution was investigated. Bean husk waste was modified using ortho-phosphoric acid. The prepared adsorbent was further characterized using FTIR, SEM, EDX and $\mathrm{pH}_{\mathrm{pzc}}$ techniques respectively. FTIR revealed prominent functional groups for IBP adsorption, SEM showed several pores on activated bean husk making it suitable for trapping IBP molecules. EDX results of acid activated bean husk has the highest percentage of carbon by weight (84.21\%) and (89.02\%) by atom, respectively. $\mathrm{pH}_{\mathrm{pzc}}$ studies revealed that the surface of the prepared adsorbent contains predominantly acidic groups: carboxyl $(0.531 \mathrm{mmol} / \mathrm{g})$, phenolic $(0.845 \mathrm{mmol} / \mathrm{g})$ and lactonic $(0.021 \mathrm{mmol} / \mathrm{g})$ totalling $1.397 \mathrm{mmol} / \mathrm{g}$ while basic group has $0.700 \mathrm{mmol} / \mathrm{g}$. Operational parameters such as: contact time, $\mathrm{pH}$, temperature, initial IBP concentrations and adsorbent dose were studied. Optimum IBP adsorption took place at a pH of 4.75. Isotherm studies were conducted using Langmuir, Freundlich, Temkin and Dubinin-Radushkevich isotherm models respectively. Langmuir isotherm aligned best with the adsorption data. The maximum monolayer adsorptive capacity of the modified adsorbent was $50.00 \mathrm{mg} / \mathrm{g}$ at $50{ }^{\circ} \mathrm{C}$. Four different kinetic models viz; pseudo first order, pseudo second order, Elovich, and Intraparticle-diffusion were used to investigate the kinetic process. Adsorption data fitted the pseudo second order kinetic model most. Thermodynamic parameters revealed that the process is spontaneous and endothermic. The study revealed that bean husk is a good precursor for activated carbon preparation; it is an efficient, readily available, economically friendly alternative for the sequestration of ibuprofen from aqueous solution.
\end{abstract}

\section{Introduction}

A wide range of chemicals with inherent detrimental effect to the body are known to exist. These chemicals are essential constituents of our daily use such as plastics, personal care products, and pharmaceutical products (Önal, 2015). However, some chemicals referred to as endocrine disruptors which are a subdivision of the wide class of emerging contaminants have the ability to alter the functions of human body endocrine (hormone) system (Natalia et al., 2014). Based on factors such as origin, uses and effects, endocrine disruptors can be grouped into natural disruptors,-(e.g. plant hormones, pharmaceuticals),environmental pollutants -(e.g. DDT) and industrially relevant chemicals which includes genistein and coumestrol, polychlorinated biphenyls, dioxins, and polyaromatic hydrocarbons, alkylphenols and bisphenol A. (Zacharewski et al., 1998; Mondal et al., 2016, Amit and Anastopoulos, 2017). 2-[4-(2-methylpropyl) phenyl] propanoic acid, commonly referred to as Ibuprofen $\left(\mathrm{C}_{13} \mathrm{H}_{18} \mathrm{O}_{2}\right)$ is one of the non-steroidal anti-inflammatory drugs (NSAIDs) that is widely available and sold over the counter. Ibuprofen is listed as one of the vital medicine compiled by the world health organization. (Natalia et al., 2014). It has been reported that the amount of IBP in the environment is within the range of $10 \mu \mathrm{g} /$ $\mathrm{L}$ and $169 \mu \mathrm{g} / \mathrm{L}$ (Dos et al., 2007, Santos et al., 2007). It is a white crystalline solid at room temperature; sparingly soluble in polar solvents such as water but completely soluble in non-polar solvents such as ethanol.

Ibruprofen is totally healthy when taken in small doses, however when taken in large doses, it usually come with health hazards. Some of the side effects that have been associated with the use of Ibruprofen include; Itchy skin, diarrhea, constipation, stomach upset, and nervousness (Anastopoulos, 2017). Ibuprofen has been discovered to exist in concentrations up to $24.6 \mu \mathrm{gL}$ in waste water treatment plants. This

\footnotetext{
* Corresponding author. Department of Pure and Applied Chemistry, Ladoke Akintola University of Technology, P.M.B. 4000, Ogbomoso, Oyo State, Nigeria.

E-mail addresses: osbello06@gmail.com, osbello@lautech.edu.ng (O.S. Bello), ocalao@student.lautech.edu.ng (O.C. Alao), tcalagbada@student.lautech.edu.ng (T.C. Alagbada), am.olatunde@ui.edu.ng (A.M. Olatunde).
} 
concentration posses a potential hazard on human health. (Kot-Wasik et al., 2007; Miège et al., 2008). Various techniques have been employed to remove endocrine disrupting chemicals (EDCs) from wastewater. This includes techniques such as adsorption (Ansari and Mohammad-Khah, 2009; Hanen et al., 2017), evaporation, ozonation (Karol et al., 2015), membrane photocatalysis (Maria et al., 2017), nanofiltration (Sadmani et al., 2012) and biological treatment processes.

Bean (Phaselous vulgaris) is one of the most common, nutritionally rich legumes with diverse tastes and flavor owing to its diverse species. The husk of bean is not edible to humans but edible to livestock, such as cattle and goats and has little economic relevance. It is always discarded as debris forming heaps which often cause environmental pollution. Bean husks are widely available and are considered as an economically viable means of preparing activated carbon. Contrary to other routes of obtaining activated carbon which entails multiple steps, bean husks can be processed into activated carbon using a single step acid activation. This process can be employed even in rural areas without the involvement of sophisticated scientific tools.

This study is therefore aimed at converting bean husk biomass residual wastes into activated carbon and investigating its potentials in the sequestration of Ibuprofen (IBP) from aqueous solution. Operational variables studied include initial IBP concentration, adsorbent administration dosage, $\mathrm{pH}$, agitation time and adsorption temperatures were examined. The kinetic of IBP sequestration studies were correlated to four different isotherm models namely: Langmuir, Freundlich, Temkin and Dubunin- Radushkevich isotherms. The data were also fitted using: pseudo first order, pseudo second order, Elovich and intra particle diffusion kinetic models.

\section{Materials and methods}

\subsection{Chemicals}

The chemicals employed for this investigation are: orthophosphoric acid $\left(\mathrm{H}_{3} \mathrm{PO}_{4}\right)$, ethanol $\left(\mathrm{CH}_{3} \mathrm{COOH}\right)$, Ibuprofen $\left(\mathrm{C}_{13} \mathrm{H}_{18} \mathrm{O}_{2}\right)$. The chemicals were of analytical grade and were therefore used without further purification.

\subsection{Collection of samples and pretreatment}

Bean husk used as a low cost agricultural waste was obtained from Wazo (an ultramodern market) in Ogbomoso (a town in the South western part of Nigeria). The husks were first washed with tap water followed by distilled water in order to remove interfering impurities. The washed samples were sun dried to constant weight and was then pulverized using mortar and pestle. This was done to increase the surface area of the sample. The pulverized bean husks were then sieved using a $106 \mu \mathrm{m}$ mesh sieve to obtain a uniform particle size.

\subsection{Preparation of activated carbon}

$20 \mathrm{~g}$ of the bean husk powder was weighed into a $1000 \mathrm{ml}$ beaker. $600 \mathrm{~cm}^{3}$ of $\mathrm{H}_{3} \mathrm{PO}_{4}$ was added. The mixture was thoroughly stirred and heated on a hot plate until uniform slurry was obtained (Olakunle et al., 2018). This was transferred into a crucible and placed inside an oven for $48 \mathrm{~h}$ at a temperature of $105^{\circ} \mathrm{C}$. The sample was allowed to cool and then was washed several times with de-ionized water until the $\mathrm{pH}$ attained was close to neutrality. The washed sample was dried in an oven at $105^{\circ} \mathrm{C}$ for $4 \mathrm{~h}$. The activated carbon obtained from the bean husk was then stored in an airtight container for subsequent experiments.

\subsection{Adsorbate preparation}

The physicochemical properties of IBP (Fig. 1) that was employed as the adsorbate are presented in Table $1.1 .0 \mathrm{~g}$ of IBP crystalline powder

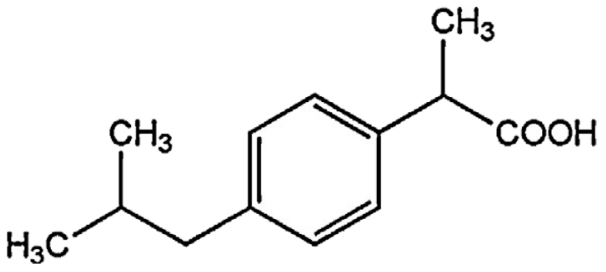

Fig. 1. Chemical structure of ibuprofen.

Table 1

Physicochemical characteristics of Ibuprofen.

\begin{tabular}{ll}
\hline Parameters & Properties \\
\hline Suggested name & Ibruprofen \\
Chemical name & 2 -(4- Isobutyl phenyl)propanoic acid \\
Chirality & Racemic mixture \\
Density & $1.03 \mathrm{~g} / \mathrm{ml}$ \\
Physical form & White crystalline powder \\
Boiling point & $157^{\circ} \mathrm{C}$ \\
Index of refraction & 1.519 \\
max & $280 \mathrm{~nm}$ \\
Molecular formula & $\mathrm{C}_{13} \mathrm{H}_{18} \mathrm{O}_{3}$ \\
Molecular weight & $206.28 \mathrm{~g} / \mathrm{mol}$ \\
\hline
\end{tabular}

was dissolved in $1000 \mathrm{ml}$ of ethanol to obtain the stock solution. Serial dilutions were prepared from the stock solution so as to acquire preferred concentrations as working solutions. IBP is partially soluble in water but completely soluble in organic solvents. For this reason, an organic solvent (ethanol) was used to dissolve the adsorbate in order to have a homogenous mixture.

\subsection{Characterization of BHAA}

\subsubsection{Fourier transform infrared spectroscopy}

The spectra of raw and acid activated bean husk were recorded on a PerkinElmer FTIR-2000 Fourier transform infrared (FTIR) spectrometer. The spectra measurement was taken within the range of 4000 to $400 \mathrm{~cm}^{-1}$ using $\mathrm{KBr}$ disc.

\subsubsection{Scanning electron microscopy (SEM)}

SEM is a brand of electronic microscope which applies rays of focused low energy electron to generate magnified images of a sample (Qu, 2009). Interactions of the shaft of electron with the atomic constituents of the sample results into generation of various signals. Information regarding the sample's surface property, constituents and its scenery are inferred from the signals generated by SEM(Ahmad et al., 2011).

\subsubsection{Energy dispersive $X$-ray}

The energy dispersive X-ray (EDX) is a tool employed for the detection of elements present in both raw and acid-activated bean husk and their respective percentages. The elemental components of the bean husk waste were elucidated by employing the EDX. The activation process was noticed to be accountable for the increase in the percentage carbon content of the bean husk (Ahmad et al., 2015).

\subsubsection{Boehm titration}

The oxygen-containing groups present on the surface of the activated carbon were determined using Boehm titration (Ahmad et al,, 2014). Boehm's Titration has its basis on the postulate that acid-base reaction in the aqueous medium is due to the presence of several basic and acidic groups which originated from diverse oxygen containing groups. (Boehm, 1996).

\subsection{5. $p H$ point of zero charge}

The $\mathrm{pH}$ of point of zero charge is the $\mathrm{pH}$ at which the total surface 
charge on the adsorbent material is zero (Russel et al.,1989). It is usually defined in terms of the solution $\mathrm{pH}$. It assists in detecting the efficiency of the adsorbent in sequestering the adsorbate.

\subsection{Adsorption experiments}

\subsubsection{Batch equilibrium method}

Adsorption efficiency of IBP onto BHAA was investigated using batch method at three different temperatures: 303, 313 and $323 \mathrm{~K}$ respectively. In depth studies were carried out on the effects on the initial IBP concentration, contact time and solution temperature on the adsorption process. Five different concentrations of IBP were studied. At each IBP concentration $0.1 \mathrm{~g}$ of BHAA was weighed into a $200 \mathrm{~mL}$ Erlenmeyer flask and $50 \mathrm{~mL}$ of IBP solution was added into the flask. Each of the flasks was continuously agitated in a water bath shaker for $3 \mathrm{~h}$ at a particular temperature until the equilibrium was attained. Small quantity of the solution was withdrawn using a $10 \mathrm{ml}$ syringe and analyzed with a UV-visible spectrophotometer (Model 6715: Jenway) which has been preset to a wavelength of $280 \mathrm{~nm}$ (Tan, 2008). This was done to determine the amount of IBP adsorbed onto the bean husk adsorbent. Equation (1) was used to calculate the amount of IBP adsorbed.

$q_{e}=\frac{\left(C_{e}-C_{o}\right) V}{W}$

where $\mathrm{C}_{\mathrm{o}}$ and $\mathrm{C}_{\mathrm{e}}(\mathrm{mg} / \mathrm{L})$ are the concentrations of the adsorbate in aqueous solution at initial and equilibrium points respectively. $\mathrm{V}$ represents the volume of the solution (in $\mathrm{dm}^{3}$ ) and $\mathrm{W}$ is the mass (in grams) of the BHAA used.

\subsubsection{Batch kinetic studies}

Aqueous samples of the solutions were withdrawn at preset time interval for the study. Measurements of IBP were taken. The amount of IBP uptake at specific time, $q_{t}(\mathrm{mg} / \mathrm{g})$, was computed using Equation (2),

$q_{t}=\frac{\left(C_{o}-C_{t}\right) V}{W}$

where $\mathrm{C}_{\mathrm{o}}$ and $\mathrm{C}_{\mathrm{t}}(\mathrm{mg} / \mathrm{g})=$ liquid-phase concentrations of IBP at initial and at equilibrium time respectively. $\mathrm{V}=$ volume of the solution $\left(\mathrm{dm}^{3}\right)$. $\mathrm{W}=$ mass $(\mathrm{g})$ of the bean husk activated carbon used.

\section{Results and discussion}

\subsection{Effects of initial IBP concentration, contact time and solution temperature}

Effect of different IBP concentrations and agitation time were examined, $50 \mathrm{~mL}$ of IBP solution with initial concentrations ranging from 20 to $100 \mathrm{mg} / \mathrm{L}$ were prepared by serial dilution in a $250 \mathrm{~mL}$ conical flasks. An equivalent amount of $0.10 \mathrm{~g}$ of BHAA was weighed into each conical flask, covered with glass cork, and the conical flasks were arranged into an isothermal water bath schematic shaker (Model NE5.28D) preset to a temperature of $303 \mathrm{~K}$ and a rotating velocity of $120 \mathrm{rpm}$ until equilibrium was attained. The influence of solution temperature on IBP adsorption was investigated by varying the adsorption temperature from 303 to $323 \mathrm{~K}$. This was achieved by regulating the temperature via its control panel on the water bath shaker. The graph depicting the uptake of BHAA at different contact times was shown in Fig. 2. It was observed from the figure that the adsorption experiment follows a dual-step process initially involving speedy adsorption for the preceding $5 \mathrm{~min}$, after which a much slower removal was observed. The highest amount of IBP adsorbed was observed beyond $20 \mathrm{~min}$ of interaction. Hence, $40 \mathrm{~min}$ was observed to be the experimental contact time for this study. The speedy uptake observed during the first $20 \mathrm{~min}$ was probably attributed to the widely available

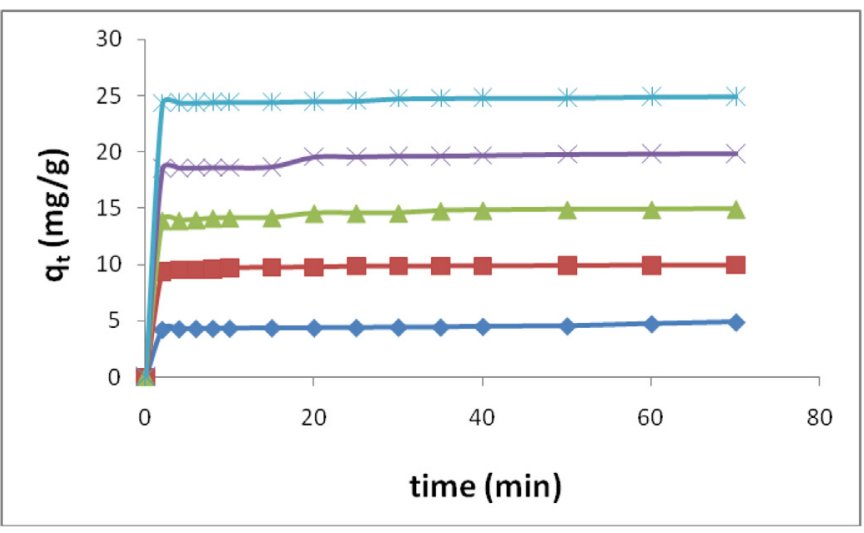

Fig. 2. Effect of contact time and initial IBP concentration.

active pores of the bean husk surface, and with the continuous uptake of the adsorbate, the adsorption became less efficient. A similar observation was observed in the study of Cd (II) and Cr (VI) biosorption by mesocarps of orange and sour orange from aqueous solutions (Zazouli et al., 2014).

The effects of the various initial IBP concentrations at varying contact time (2-70 min) on the uptake of IBP at $\mathrm{pH} 4.75$ for BHAA is shown in Fig. 2. The percentage removal decreased from 95.28 to $78.17 \%$ with the increase of initial IBP concentrations in the range of $10-50 \mathrm{mg} / \mathrm{L}$, however, the amount adsorbed at equilibrium $\left(\mathrm{q}_{\mathrm{e}}\right)$ ranged from 4.95 to $24.57 \mathrm{mg} / \mathrm{g}$. Literature revealed that Sui et al. (2011) investigated the initial concentration of phenol adsorbed using bean husk, the $\mathrm{q}_{\mathrm{e}}$ was found to increase from 1.41 to $16.64 \mathrm{mg} / \mathrm{g}$ with increasing Phenol concentration from 10 to $50 \mathrm{mg} / \mathrm{L}$. Similar trend was also recorded by Balarak Davoud (2016) in the adsorption of Bisphenol A onto Barley husk biomass.

\subsection{Activation of the adsorbent using ortho-phosphoric acid}

Ortho-phosphoric acid (PA), promotes bond cleavage in agricultural wastes through dehydration at low temperatures (Girgis and ElHendawy, 2002; Venersson et al., 2002; Guo and Lua, 2003; Diao et al., 2002). This is followed by extensive cross linking that binds volatile matter into the carbon products and thus increases the carbon yield. Benaddi et al. (1998) showed that the mechanism of PA activation of biomass occurs through various steps: cellulose de-polymerization, biopolymer dehydration, formation of aromatic rings and elimination of phosphate groups. This produces activated carbon with good yields and high surface areas. Activation conditions thus depend on the nature of the precursor, i.e on the relative amounts of cellulose, hemicelluloses, lignin and ashes. In the present study, authors prepared ACs from bean husk (BH) by activation with $\mathrm{H}_{3} \mathrm{PO}_{4}$, the optimum BH/PA weight/volume ratio allowing complete activation of $\mathrm{BH}$ was evidenced when $25.0 \pm 0.01 \mathrm{~g}$ of powdered $\mathrm{BH}$ was impregnated with $500 \mathrm{~cm}^{3}$ of $0.3 \mathrm{~mol} / \mathrm{dm}^{3}$ ortho-phosphoric acid $\left(\mathrm{H}_{3} \mathrm{PO}_{4}\right)$. The best yield was obtained using this weigh/volume ratio. Alteration in the ratio of $\mathrm{BH} / \mathrm{PA}$ did not produce good yield during pyrolysis (Fierro et al., 2005). Hence, this ratio was used for the acid activation.

\subsection{Characterization of adsorbent}

\subsubsection{Fourier transform infrared (FTIR)}

The typical functional groups inherent on the surfaces of raw (RBH) and activated bean husk (BHAA) as revealed by the FTIR are shown in Fig. 3a and b. These figures show the emergence, shift and disappearance of several peaks which are attributed to certain functional groups. The various band assignments are presented in Table 2. BHAA has notable and prominent groups such as $\mathrm{O}-\mathrm{H}$ stretch of alcohols, 


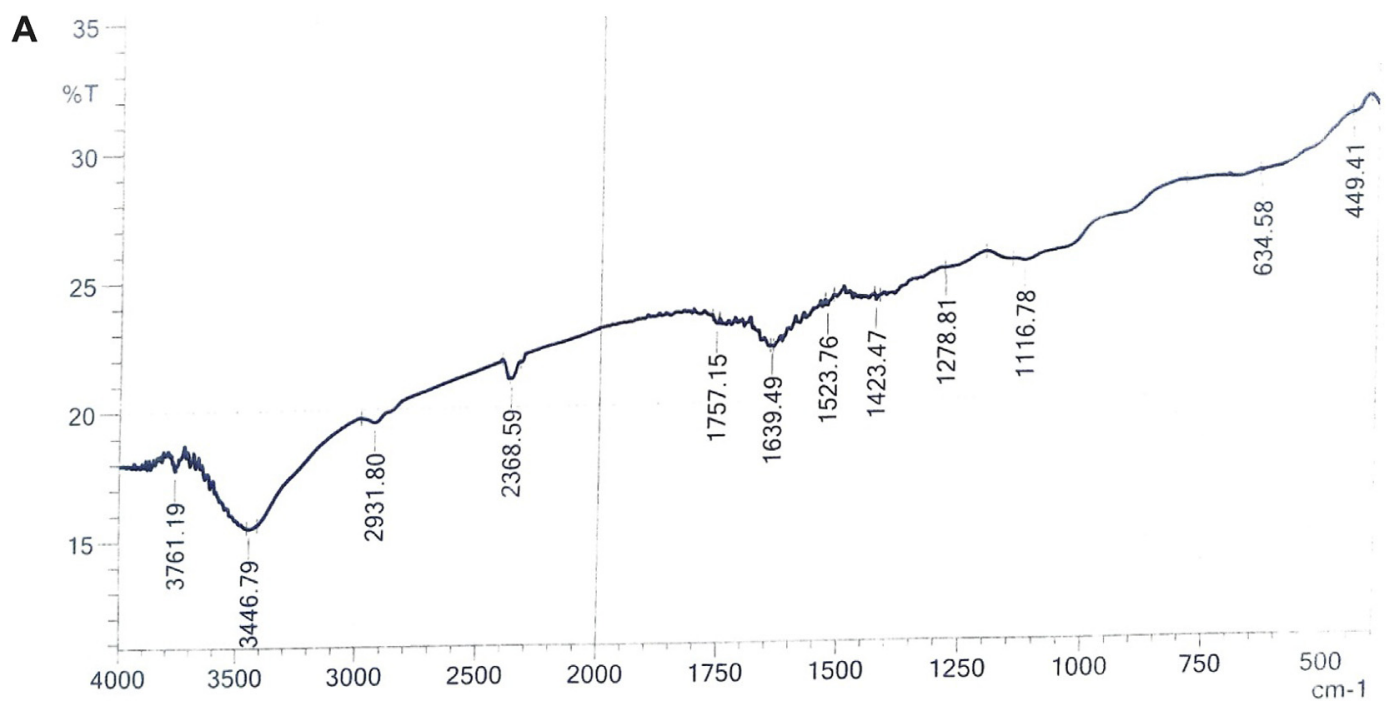

Fig. 3a. FTIR spectrum of raw bean husk.

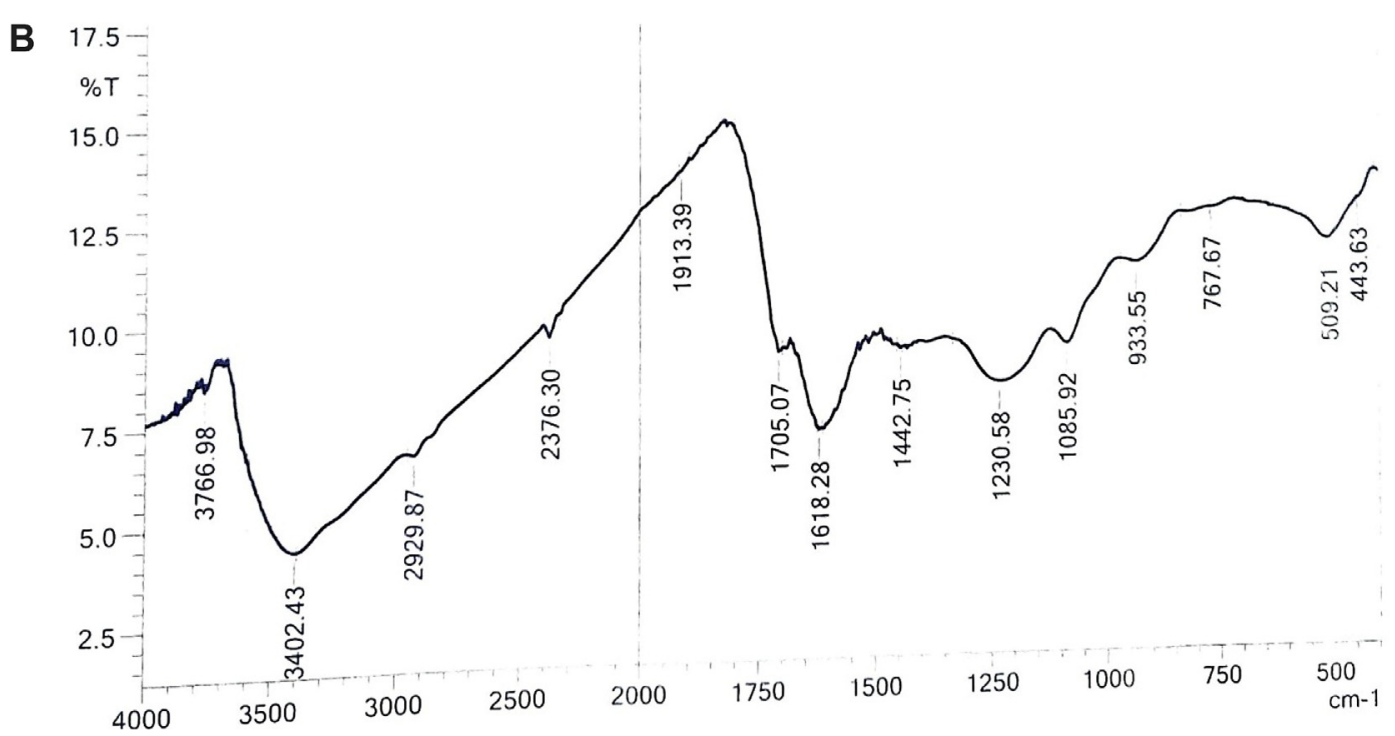

Fig. 3b. FTIR spectrum of acid activated bean husk.

Table 2

FTIR characteristics of bean husk adsorbent.

\begin{tabular}{lllll}
\hline \multicolumn{4}{l}{ IR Wave number $\left(\mathrm{cm}^{-1}\right)$} & \\
\hline IR & RBH & BHAA & Differences & Band Assignments \\
\hline 1 & 3761 & 3766 & +5 & O-H stretch of bonded hydroxyls \\
2 & 3446 & 3402 & -42 & O-H stretch of alcohols, phenols \\
3 & 2931 & 2929 & +2 & C-H stretch of alkanes \\
4 & 2368 & 2376 & -8 & C $=$ C stretch of alkynes \\
5 & 1757 & 1705 & +52 & C=O stretch of ketones, lactones, and \\
& & & & carboxylic anhydrides \\
6 & 1639 & 1618 & +21 & C=O stretch of carboxylic acids \\
7 & 1523 & 1442 & +81 & C=C- stretch of alkenes \\
8 & 1423 & 1422 & +1 & C-C stretch of aromatics \\
9 & 1278 & 1085 & +193 & C-O stretch of alcohol \\
10 & 1116 & 933 & +183 & C=O bonds of esters, ethers and phenol \\
11 & 635 & 509 & +126 & O=H bend of carboxylic acids \\
\hline
\end{tabular}

phenols $\left(3402 \mathrm{~cm}^{-1}\right), \mathrm{C}-\mathrm{H}$ stretch of alkanes $\left(2929 \mathrm{~cm}^{-1}\right), \mathrm{C}=\mathrm{O}$ stretch of ketones, lactones, and carboxylic anhydrides $\left(1705 \mathrm{~cm}^{-1}\right)$ and $\mathrm{C}=\mathrm{O}$ stretch of carboxylic acids $\left(1618 \mathrm{~cm}^{-1}\right)$ for IBP adsorption. Similar results were obtained in a study of adsorption of ibuprofen from

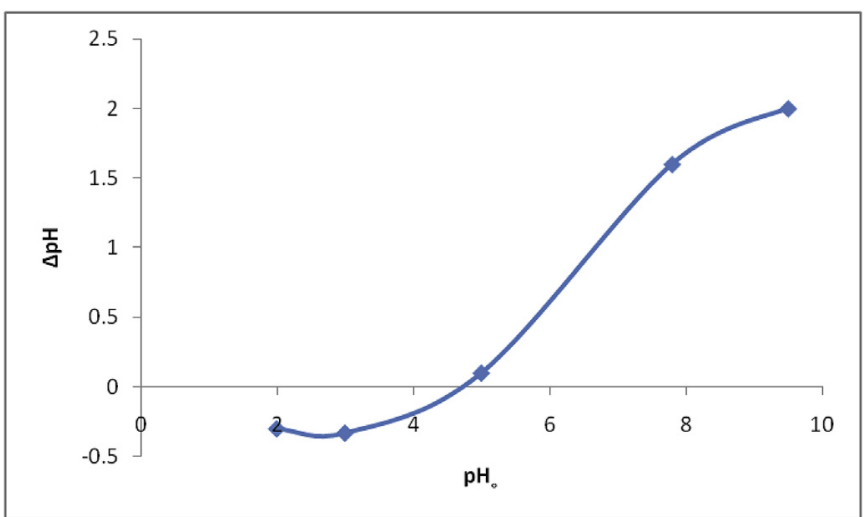

Fig. 4. Plot of $\mathrm{pH}$ Point of zero charge of acid activated bean husk.

aqueous solution on chemically surface-modified activated carbon cloths (Guedidi et al., 2017).

\subsection{2. pH point of zero charge}

The $\mathrm{pH}$ point of zero charge $\left(\mathrm{pH}_{\mathrm{pzc}}\right)$ of BHAA was determined. The 


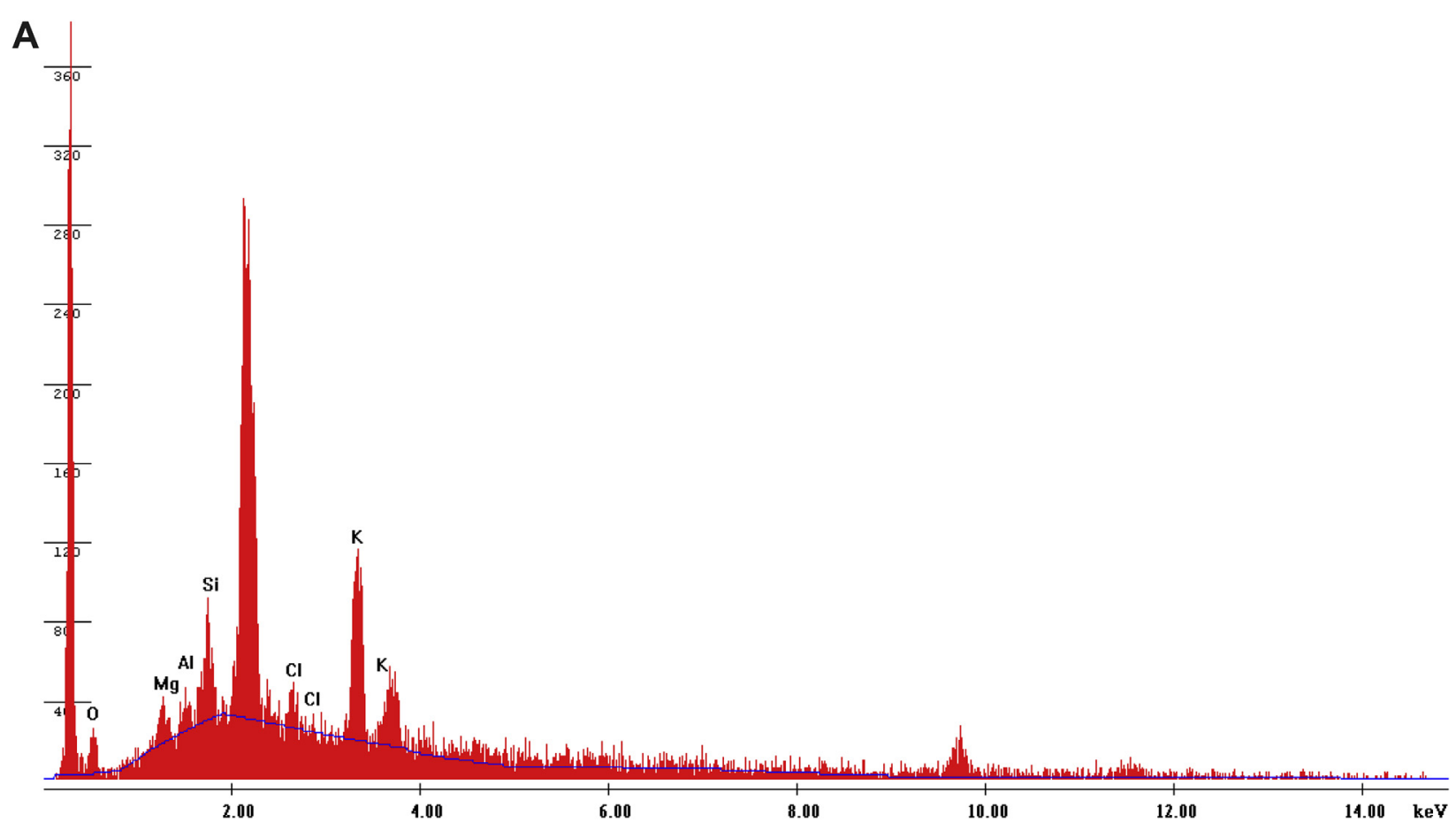

Fig. 5a. EDX spectra of raw bean husk.

B

$\mathbf{B}_{180}$

$\overline{160}$

$\overline{140}$

$\overline{120}$

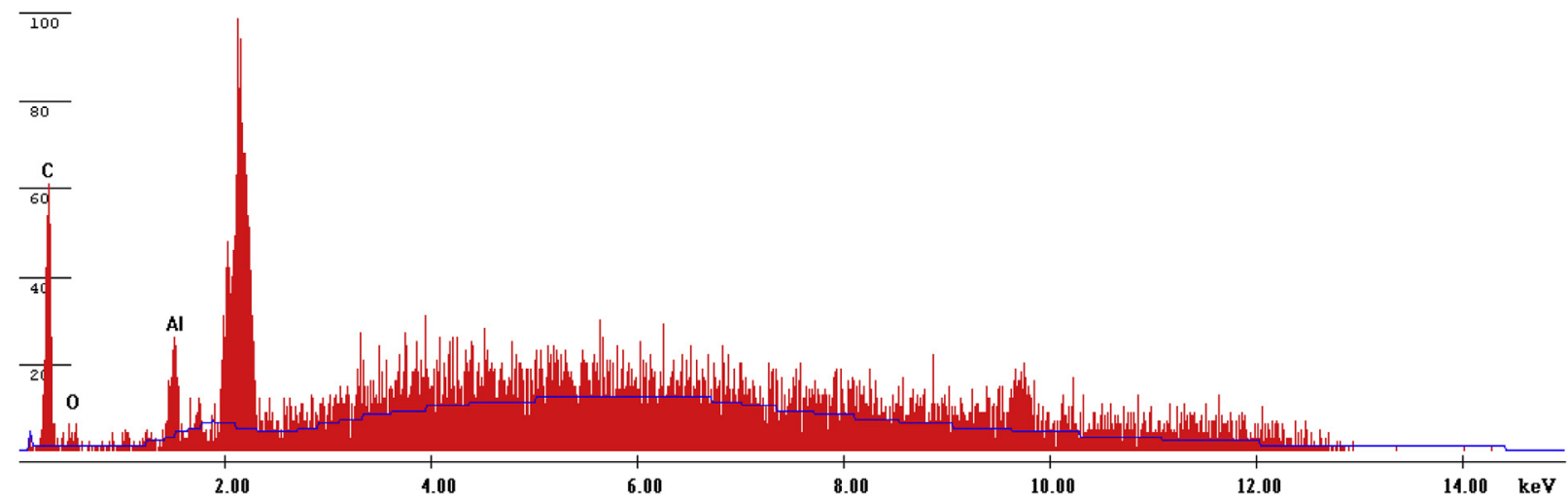

Fig. 5b. EDX spectra of acid activated bean husk.

value was obtained from the point where the resulting curve cut through the $\mathrm{pH}_{0}$ axis as presented in Fig. 4. The $\mathrm{pH}_{\mathrm{pzc}}$ was found to be 4.75 for BHAA. Adsorption of cations are favored at $\mathrm{pH}$ higher than the $\mathrm{pH}_{\mathrm{pzc}}$ (Ferahani et al., 2011). Fig. 4 shows the graph of $\mathrm{pH}$ point of zero charge of activated bean husk.

\subsubsection{Energy dispersive $X$-ray (EDX)}

The percentage composition of the elements in BHAA was determined from the EDX spectra (Fig. $5 \mathrm{a}$ and b). Carbon has the highest weight percent when compared with other constituent elements detected in the sample (Table 3). The high percentage of carbon present suggests that bean husk is an efficient, excellent and appropriate precursor for the preparation of activated carbon (Bello et al., 2012). There is an increase in the weight percent of carbon and oxygen content ranged from $84.21 \%$ to $6.3 \%-89.02 \%$ to $7.98 \%$ respectively in BHAA. A similar result was obtained from a study on sustainable conversion of agro-wastes into useful adsorbents (Bello et al., 2016, Ojedokun and Bello, 2017). 
Table 3

EDX characteristics of bean husk adsorbent.

\begin{tabular}{lll}
\hline Elements & RBH (wt \%) & BHAA (At \%) \\
\hline $\mathrm{C}$ & 84.21 & 89.02 \\
$\mathrm{O}$ & 6.3 & 7.98 \\
$\mathrm{Mg}$ & 0.85 & Nil \\
$\mathrm{Al}$ & 0.55 & 3.00 \\
$\mathrm{Si}$ & 1.83 & Nil \\
$\mathrm{Ca}$ & 0.53 & Nil \\
$\mathrm{K}$ & 5.43 & Nil \\
$\mathrm{Cl}$ & 0.76 & Nil \\
$\mathrm{Fe}$ & $\mathrm{Nil}$ & Nil \\
$\mathrm{P}$ & $\mathrm{Nil}$ & Nil \\
$\mathrm{Total}$ & 100 & 100 \\
\hline
\end{tabular}

\subsubsection{Scanning electron micrograph (SEM)}

The Scanning electron micrograph (SEM) images of RBH and BHAA are presented as Fig. $6 \mathrm{a}$ and $\mathrm{b}$. It was observed that RBH surface was uneven and the pores aren't appropriately developed, they are irregular whereas in the SEM for BHAA the pores are well developed, prominent and regular. This is due to the acid activation process in the preparation of the adsorbent. These well developed, regular and prominent pores enhance the trapping of the adsorbate onto the adsorbent (Ahmad et al., 2014, 2015).

\subsubsection{Boehm's titration}

Boehm's examination of the surface chemistry of the activated carbon requires the use of acid/base titration method. Prior to the evaluation of surface acidity and basicity of the activated carbon, it was presume that neutralization of acidic group can only be brought about by: $\mathrm{NaOH}, \mathrm{Na}_{2} \mathrm{CO}_{3}$, and $\mathrm{NaHCO}_{3}$, while $\mathrm{HCl}$ is the only chemical capable of neutralizing the basic groups. Properties of the surface of BHA inferred from Boehm's titration were presented in Table 4. Results obtained are as follows: carboxyl $(0.531 \mathrm{mmol} / \mathrm{g})$, phenolic $(0.845 \mathrm{mmol} /$ $\mathrm{g})$ and lactonic $(0.021 \mathrm{mmol} / \mathrm{g})$. The total acidic group $(1.418 \mathrm{mmol} / \mathrm{g})$ and the total amount of basic group $(0.700 \mathrm{mmol} / \mathrm{g})$. This revealed that the surface of BHAA was predominantly acidic favoring adsorption of cationic molecules (Bello et al., 2017).

\subsubsection{Adsorption kinetic studies}

Adsorption kinetic data of IBP uptake were correlated using four different kinetic models: pseudo first-order (Lagergren and Svenska, 1898), pseudo second-order (Ho and McKay, 1999), Elovich and Intraparticle diffusion model (Weber and Morris, 1963). The rate-determining step of the adsorption exercise and the adsorption mechanism were deduced from the adsorption data. Pseudo-second-order kinetic models fit the adsorption data most when compared to other kinetic models. The values reported in Table 5 showed that the IBP adsorption parameters gave good agreement with the pseudo-secondorder kinetic model with $\mathrm{R}^{2}$ value close to unity and low values of SSE. The rate coefficient, $\mathrm{k}_{2}$, of pseudo second-order was found to increase with increase in initial IBP concentration. It indicates that as the initial concentration increases, the electrostatic interaction increased on the site, thus enhancing the affinity of IBP toward the adsorbent (Chu, 2002). However, Elovich desorption constant, $\beta$, decreases as the initial IBP concentration increases, and this is related to the extent of surface coverage and activation energy for the chemisorptions process. Similarly, the Elovich constant, $\alpha$, decreased with increase in initial IBP concentration. This indicates that the adsorption process involves more than one mechanism. The findings were in agreement with several

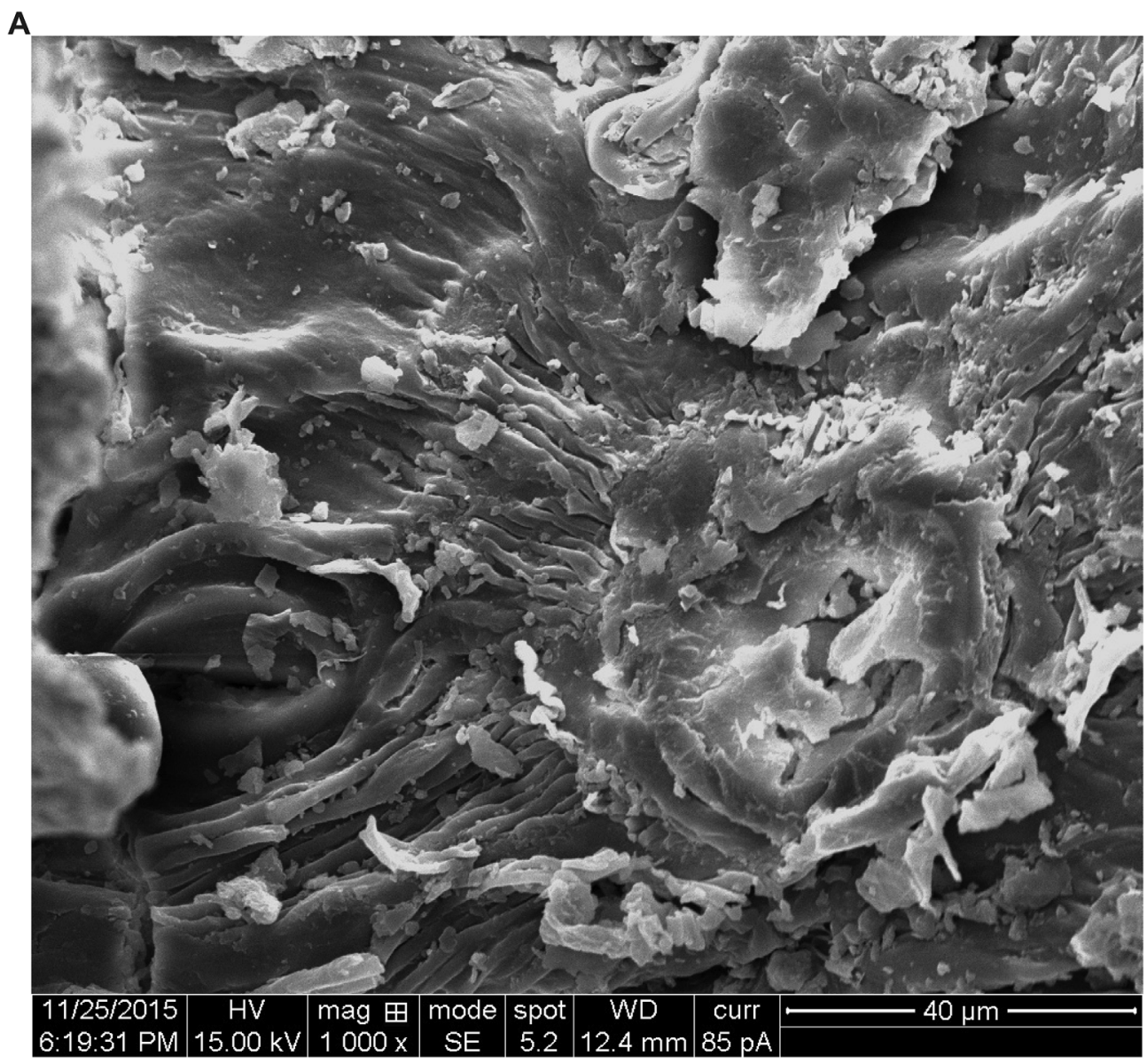

Fig. 6a. SEM Micrograph of raw bean husk. 


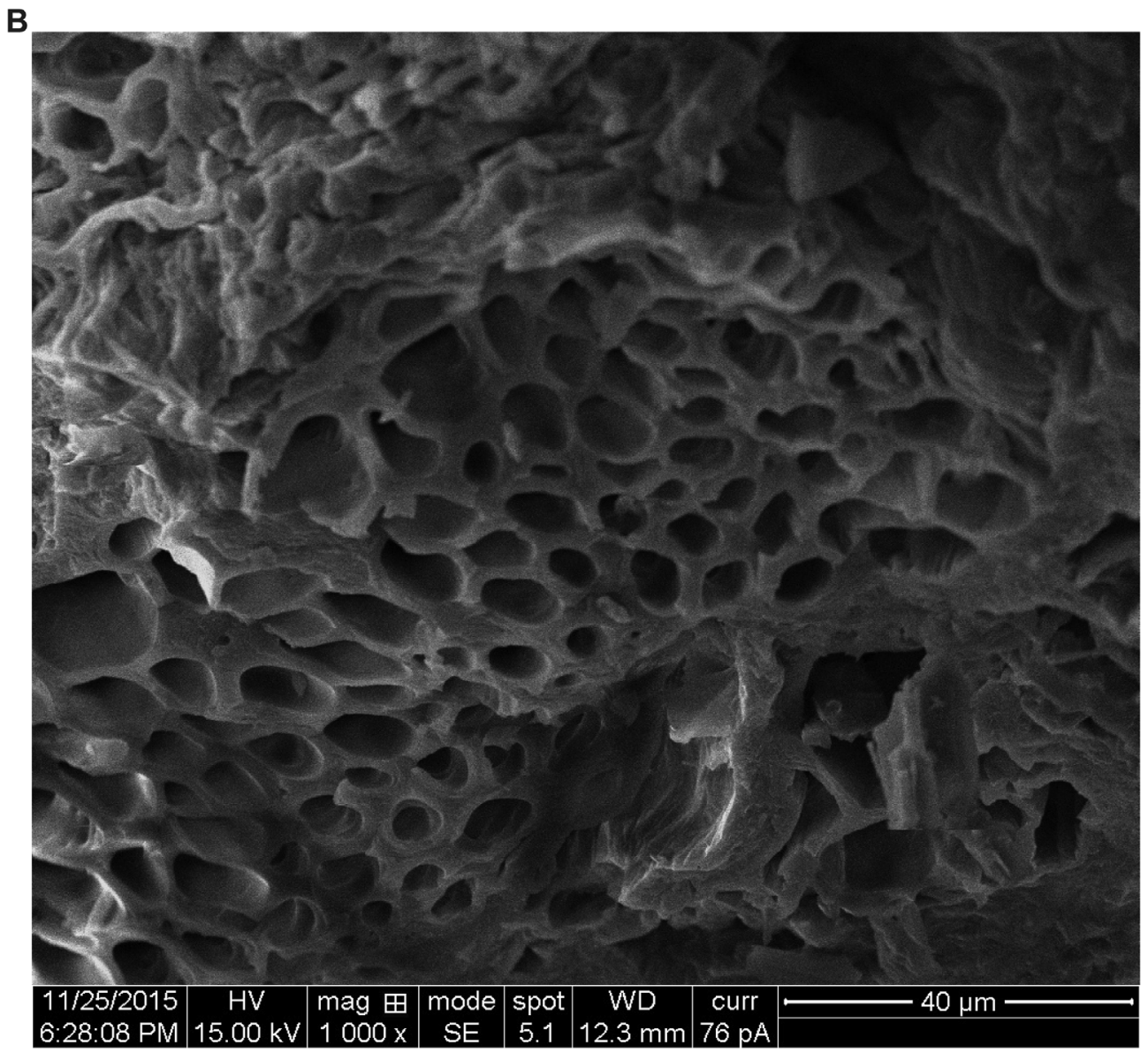

Fig. 6b. SEM Micrograph of acid bean husk.

Table 4

Boehm titration values of acid activated Bean Husk. The values reported are mean of triplicates. The standard error is \pm 0.001 .

\begin{tabular}{llllll}
\hline Adsorbent & \multicolumn{3}{l}{ Boehm's Titration result } & & \\
\cline { 2 - 6 } & $\begin{array}{l}\text { Carboxylic } \\
(\mathrm{mmol} / \mathrm{g})\end{array}$ & $\begin{array}{l}\text { Phenolic } \\
(\mathrm{mmol} / \mathrm{g})\end{array}$ & $\begin{array}{l}\text { Lactonic } \\
(\mathrm{mmol} / \mathrm{g})\end{array}$ & $\begin{array}{l}\text { Basicity } \\
(\mathrm{mmol} / \mathrm{g})\end{array}$ & $\begin{array}{l}\text { Acidity } \\
(\mathrm{mmol} / \mathrm{g})\end{array}$ \\
\hline BHA & 0.531 & 0.845 & 0.021 & 0.700 & 1.397 \\
\hline
\end{tabular}

studies on the adsorption of IBP onto Modifed Chitosan (Bany-Aiesh et al, 2015), Honey comb (Dubey et al., 2010), AC from artemisia vulgaris (Dubey et al., 2010) and AC from olive waste cake (Baccar et al., 2012) respectively.

\subsubsection{Adsorption isotherm studies}

This was examined by correlating the adsorption data obtained at equilibrium to four diverse isotherm models which are: Langmuir, (1918), Freundlich (Freundlich, 1906), Temkin (Temkin and Pyzhev,

Table 5

Parameters of various kinetic models of IBP adsorption onto BHAA at $313 \mathrm{~K}$.

\begin{tabular}{|c|c|c|c|c|c|c|}
\hline \multirow[t]{2}{*}{ Kinetic models } & \multirow[t]{2}{*}{ Parameters } & \multicolumn{5}{|c|}{ Initial dye concentration } \\
\hline & & $10 \mathrm{mg} / \mathrm{L}$ & $20 \mathrm{mg} / \mathrm{L}$ & $30 \mathrm{mg} / \mathrm{L}$ & $40 \mathrm{mg} / \mathrm{L}$ & $50 \mathrm{mg} / \mathrm{L}$ \\
\hline \multirow[t]{5}{*}{ Pseudo-first order } & $\mathrm{q}_{\mathrm{e}(\exp )}(\mathrm{mg} / \mathrm{g})$ & 4.950 & 9.970 & 14.900 & 19.810 & 24.570 \\
\hline & $\mathrm{k}_{1}(\min )$ & 0.034 & 0.021 & 0.017 & 0.014 & 0.009 \\
\hline & $\mathrm{q}_{\mathrm{e}(\mathrm{cal})}(\mathrm{mg} / \mathrm{g})$ & 0.990 & 0.833 & 0.668 & 0.267 & 0.687 \\
\hline & $\mathrm{R}^{2}$ & 0.963 & 0.848 & 0.876 & 0.901 & 0.939 \\
\hline & SSE $\%$ & 1.770 & 4.086 & 6.364 & 8.740 & 10.680 \\
\hline \multirow[t]{5}{*}{ Pseudo-second order } & $\mathrm{q}_{\mathrm{e}(\mathrm{cal})}(\mathrm{mg} / \mathrm{g})$ & 4.975 & 10.000 & 14.900 & 19.810 & 24.570 \\
\hline & $\mathrm{k}_{2}(\min )$ & 0.116 & 0.123 & 0.145 & 0.167 & 0.185 \\
\hline & $\mathrm{h}(\mathrm{mg} / \mathrm{gmin})$ & 2.882 & 12.346 & 32.258 & 33.333 & 62.500 \\
\hline & $\mathrm{R}^{2}$ & 0.999 & 0.999 & 0.999 & 0.997 & 0.997 \\
\hline & SSE $\%$ & 0.011 & 0.013 & 0.011 & 0.090 & 0.080 \\
\hline \multirow[t]{3}{*}{ Elovich } & $\mathrm{R}^{2}$ & 0.969 & 0.882 & 0.845 & 0.838 & 0.979 \\
\hline & $\alpha(\mathrm{mg} / \mathrm{gmin})$ & $3.14 \mathrm{E}+37$ & $1.35 \mathrm{E}+34$ & $3.01 \mathrm{E}+30$ & $2.11 \mathrm{E}+26$ & $5.49 \mathrm{E}+23$ \\
\hline & $\beta(\mathrm{g} / \mathrm{mg})$ & 3.717 & 3.46 & 3.195 & 2.756 & 2.241 \\
\hline \multirow[t]{3}{*}{ Intraparticle } & $\mathrm{R}^{2}$ & 0.842 & 0.946 & 0.961 & 0.906 & 0.895 \\
\hline & $k_{\text {diff }}(\mathrm{mg} / \mathrm{g})$ & 0.019 & 0.015 & 0.012 & 0.009 & 0.006 \\
\hline & $\mathrm{C}$ & 4.180 & 9.241 & 14.290 & 19.530 & 23.900 \\
\hline
\end{tabular}

The values reported are mean of triplicates. The standard error is \pm 0.001 . 


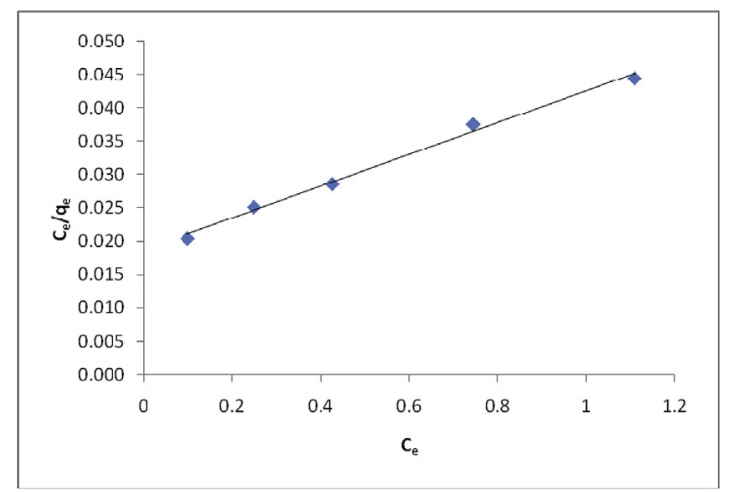

(a)

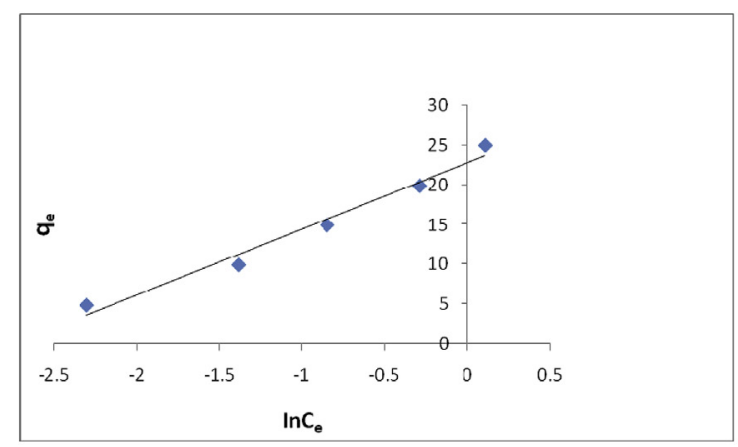

(b)

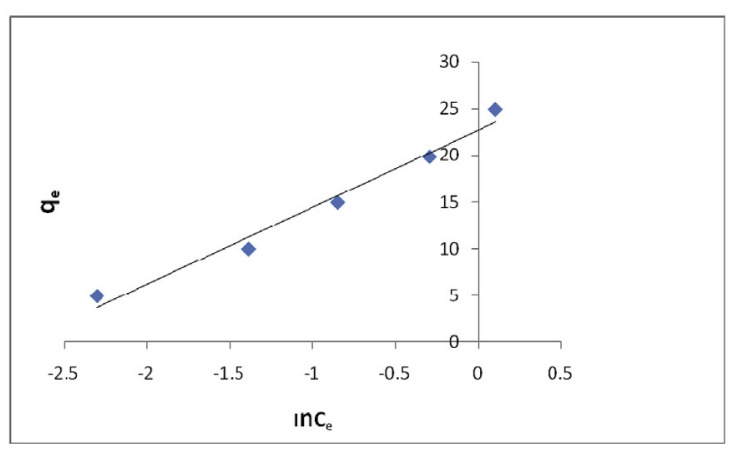

(c)

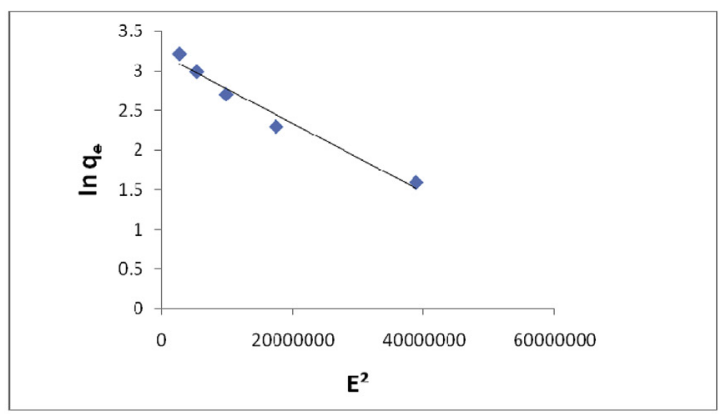

(d)

Fig. 7. Adsorption isotherms (a); Langmuir (b); Freundlich (c), Temkin (d) Dubinin-Radushkevich.

1940) and Dubinin-Radushkevich (Dubinin and Radushkevich, 1947) (Fig. 7a-d) respectively. These isotherms were employed to explain the relationships which exist between the amount of IBP bio-sorbed and its corresponding equilibrium concentrations in solutions.

The values of the maximum amount adsorbed $\left(\mathrm{Q}_{\mathrm{m}}\right)$, correlation
Table 6

The adsorption isotherm constants for the removal IBP onto BHAA.

\begin{tabular}{|c|c|c|c|}
\hline Isotherm model & $303 \mathrm{~K}$ & $313 \mathrm{~K}$ & $323 \mathrm{~K}$ \\
\hline \multicolumn{4}{|l|}{ Langmuir } \\
\hline $\mathrm{Q}_{\mathrm{m}}(\mathrm{mg} / \mathrm{g})$ & 32.258 & 43.478 & 50.000 \\
\hline $\mathrm{K}_{\mathrm{L}}(\mathrm{L} / \mathrm{mg})$ & 0.004 & 0.015 & 0.019 \\
\hline $\mathrm{R}_{\mathrm{L}}$ & 4.428 & 1.278 & 1.000 \\
\hline $\mathrm{R}^{2}$ & 0.992 & 0.993 & 0.985 \\
\hline \multicolumn{4}{|l|}{ Freundlich } \\
\hline $\mathrm{K}_{\mathrm{F}}$ & 31.623 & 24.430 & 25.760 \\
\hline $\mathrm{n}$ & 1.767 & 1.479 & 1.361 \\
\hline $\mathrm{R}^{2}$ & 0.926 & 0.991 & 0.980 \\
\hline \multicolumn{4}{|l|}{ Temkin } \\
\hline B & 350.367 & 314.66 & 120.09 \\
\hline $\mathrm{R}^{2}$ & 0.996 & 0.976 & 0.873 \\
\hline $\mathrm{K}_{\mathrm{T}}$ & 38.456 & 15.638 & 3.476 \\
\hline \multicolumn{4}{|c|}{ Dubinin-Radushkevich (D-R) } \\
\hline $\mathrm{Q}_{\mathrm{o}}(\mathrm{mg} / \mathrm{g})$ & 27.771 & 24.656 & 52.665 \\
\hline$\beta\left(\mathrm{mol}^{2} \mathrm{kj}^{-2}\right)$ & $3 \mathrm{E}-7$ & $4 \mathrm{E}-8$ & $2 \mathrm{E}-7$ \\
\hline $\mathrm{E}(\mathrm{kJ} / \mathrm{mol})$ & 1.29 & 3.54 & 1.58 \\
\hline $\mathrm{R}^{2}$ & 0.998 & 0.969 & 0.950 \\
\hline
\end{tabular}

The values reported are mean of triplicates. The standard error is \pm 0.001 .

coefficient $\left(\mathrm{R}^{2}\right)$, and the other parameters for all the isotherms are shown in Table 6. For the Langmuir isotherm, the $Q_{m}$ value of $50.00 \mathrm{mg} / \mathrm{g}$ was obtained and the value of $\mathrm{R}^{2}$ of 0.985 at $323 \mathrm{~K}$ shows good fitting of this isotherm to the experimental data (Table 6). For the Freundlich isotherm, the values of $n=1.361$ and $1 / n=0.735$ indicate that both the physical process and the normal Langmuir isotherm are favorable. The values of the empirical parameter $1 / \mathrm{n}$ observed to be less than 1 signifies an efficient adsorption. It was also noticed that the adsorptive capacity of BHAA decline with elevating temperature for the Freundlich isotherm model. Higher value for $K_{F}$ indicates higher affinity for IBP, it was noticed that the $\mathrm{K}_{\mathrm{F}}$ value at $323 \mathrm{~K}$ is approximately 1.22 times lesser than that of $303 \mathrm{~K}$. The fitting of the Freundlich isotherm to the experimental data is $\left(\mathrm{R}^{2}=0.980\right)$. For the Temkin isotherm, the constant $\mathrm{B}$ is related to the heat of adsorption, and the positive value found $(B=120.09)$ indicates an endothermic process. The fit to experimental data $\left(R^{2}=0.873\right)$.

From the analysis of all the isotherms and the knowledge of one of the most important parameters $\left(\mathrm{R}^{2}\right)$, the isotherms can be arranged according to their capacity to predict their efficiency in predicting the experimental behavior of the BHAA-IBP system. With respect to $\mathrm{R}^{2}$ (in descending order): Langmuir $>$ Freundlich $>$ D-R $>$ Temkin.

Therefore, considering the highest $\mathrm{R}^{2}$ values, the Langmuir model is the most appropriate for the adsorption of the IBP onto BHAA. The value of $E_{a}$ obtained in D-R isotherm was found to range between 1.29 and $3.54 \mathrm{~kJ} / \mathrm{mol}$ (Table 6). Since $\mathrm{E}_{\mathrm{a}}<8 \mathrm{~kJ} / \mathrm{mol}$, it suggests that the adsorption mechanism is physical in nature (Helfferich, 1962). Evaluation of the maximum single layer adsorption characteristics of BHAA compared with other studies documented in the literature revealed that BHAA is an efficient promising adsorbent (Table 7). An analogous result was documented for the adsorption of bisphenol using Red mud and Azolla filiculides (Zazouli et al., 2013; Diyanati et al., 2013).

\subsubsection{Adsorption thermodynamics}

Adsorption thermodynamic studies were investigated as a function of temperature and the thermodynamic parameters such as: as standard free energy $\left(\Delta \mathrm{G}^{0}\right)$ standard enthalpy change $\left(\Delta \mathrm{H}^{0}\right)$ and standard entropy changes $\left(\Delta S^{0}\right)$ which are important in determining the feasibility, spontaneity and the nature of adsorbate-adsorbent interactions. The values of $\Delta \mathrm{H}$ and $\Delta \mathrm{S}$ were obtained, respectively, from the slope and intercept of the Van't Hoff plot of $\ln \mathrm{K}_{0}$ versus $1 / \mathrm{T}$. (Figure not shown). Thermodynamic parameters for this adsorption process are tabulated in Table 8. The negativity of the values of free energy affirms the 
Table 7

Comparism of the maximum monolayer adsorption of IBP on various adsorbents.

\begin{tabular}{|c|c|c|c|}
\hline Adsorbent & Adsorbent Capacity $\mathrm{Q}_{\mathrm{m}}(\mathrm{mg} / \mathrm{g})$ & Temp. (K) & References \\
\hline Modifed Chitosan & 32.19 & 303 & Bany-Aiesh et al, 2015 \\
\hline Honey comb & 4.49 & 303 & Dubey et al., 2010 \\
\hline AC from artemisia vulgaris & 16.73 & 313 & Dubey et al., 2010 \\
\hline AC from olive waste cake & 9.09 & 313 & Baccar et al., 2012 \\
\hline Bean Husk activated carbon & 50 & 323 & This work. \\
\hline
\end{tabular}

Table 8

Thermodynamic parameters for the adsorption of IBP using BHAA.

\begin{tabular}{|c|c|c|c|c|c|}
\hline Temp (K) & $\Delta \mathrm{G}^{0}\left(\mathrm{kJmol}^{-1}\right)$ & $\Delta \mathrm{H}^{0}\left(\mathrm{kJmol}^{-1}\right)$ & $\Delta \mathrm{S}^{0}\left(\mathrm{kJmol}^{-1}\right)$ & $\mathrm{E}_{\mathrm{a}}\left(\mathrm{kJmol}^{-1}\right)$ & $A\left(10^{5}\right)$ \\
\hline 303 & -26.678 & 96.234 & 109.111 & 40.362 & 37.920 \\
\hline 313 & -24.311 & & & & \\
\hline 323 & -16.287 & & & & \\
\hline
\end{tabular}

The values reported are mean of triplicates. The standard error is \pm 0.001 .

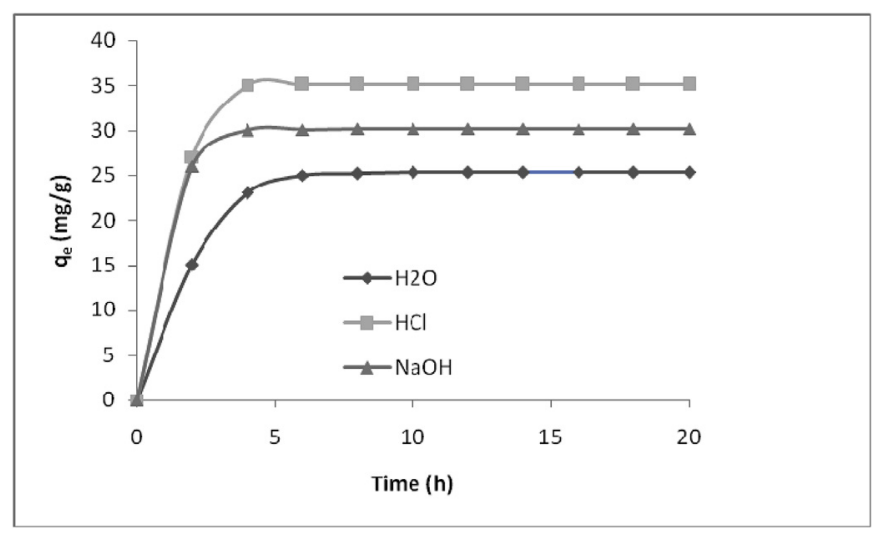

Fig. 8. Desorption curves of IBP from BHAA.

Table 9

Percentage IBP desorbed on regenerated BHAA.

\begin{tabular}{lllllll}
\hline \multicolumn{5}{c}{ Percentage IBP desorbed } \\
\cline { 3 - 6 } & \multicolumn{5}{c}{ Repeated adsorption-desorption studies } \\
\cline { 3 - 6 } & \multicolumn{5}{c}{ With 0.2 M HCl } \\
\hline EDC & Adsorbent & Without HCL & I Cycle & II Cycle & III Cycle & IV Cycle \\
IBP & BHAA & 60.45 & 88.75 & 91.32 & 93.19 & 94.68 \\
\hline
\end{tabular}

The values reported are mean of triplicates. The standard error is \pm 0.001 .

spontaneity of the adsorption experiment, positive values of the enthalpy change affirms that the adsorption process is spontaneous in nature; the positive value of the entropy change depicts increased randomness at solid-liquid interface during the experiment. The value of $E_{a}$ is $40.362 \mathrm{~kJ} / \mathrm{mol}$, further establishing the fact that adsorption process is physical in nature.

\subsubsection{Desorption and regeneration studies}

Desorption helps to understand the nature of adsorption and regeneration of the spent adsorbent. If the adsorbed IBP can be desorbed using water, then the attachment of such EDC to the adsorbent is by weak bonds. If the desorption is by using acid or alkaline, then the adsorption is by ion exchange. However, if organic acids can desorb the IBP, then it is held to the adsorbent through chemisorptions. The effect of various reagents used for desorption studies indicated that $\mathrm{HCl}$ is a better reagent for desorption because we could get $(35 \mathrm{mg} / \mathrm{l}, 30 \mathrm{mg} / \mathrm{l}$ and $25 \mathrm{mg} / \mathrm{l}$ ) removal of adsorbed IBP molecules for $\mathrm{HCl}, \mathrm{NaOH}$ and $\mathrm{H}_{2} \mathrm{O}$ respectively after $20 \mathrm{~h}$ of contact between the loaded matrix and the desorbing agents, It was also observed that equilibrium was reached in $10 \mathrm{~h}$ (Fig. 8). This is expected because desorption depends on size of the molecule, number of contact points, surface concentration, temperature and concentration of adsorbed species in solution (Th. Tadros, 1998). In the absence of competition from other adsorbates, large adsorbed molecules are unlikely to desorp on dilution with water (Daifullah et al., 2004). Such molecules will have several contact points leading to large net adsorption energy. Under acidic conditions, IBP is displaced by protons from their binding sites. It was subjected to adsorption-desorption cycles through regeneration step in between. The regeneration efficiency increased from 88.75 to $94.68 \%$ when $0.2 \mathrm{M}$ $\mathrm{HCl}$ was used in desorbing IBP from BHAA. There was a decrease in efficiency when the adsorbent was used without $\mathrm{HCl}$ treatment (Table 9).

\section{Conclusions}

This study investigated the adsorption potential of bean husk waste for the removal of IBP from aqueous solutions. It was revealed from experiments that bean husks are versatile precursors in the preparation of low-cost alternative adsorbents. Optimum IBP adsorption took place at a $\mathrm{pH}$ of 4.75. Prominent and widened pores of the BHAA due to acid activation enhanced the uptake of IBP. Adsorption data were best correlated with the Langmuir Isotherm Model and the pseudo second order kinetic model. $\Delta \mathrm{G}^{0}$ confirms the feasibility of the reaction and spontaneity of the adsorption experiment. This study reveals that bean husk waste was both efficient as well as inexpensive adsorbent for the removal of IBP from aqueous solutions.

\section{Declaration}

The authors declare no conflict of interest.

\section{Acknowledgements}

The first and corresponding author acknowledge the supports gotten from The World Academy of Science (TWAS) in form of Research grants; Research Grant number: 11-249 RG/CHE/AF/AC_1_UNESCO FR: 3240262674 (2012), 15-181 RG/CHE/AF/AC_1_: 3240287083 (2015) for the purchase of Research Equipments and LAUTECH 2016 TET Fund Institution Based Research Intervention (TETFUND/DESS/ UNI/OGBOMOSO/RP/VOL. IX) respectively.

\section{Appendix A. Supplementary data}

Supplementary data to this article can be found online at https:// 
doi.org/10.1016/j.scp.2019.100151.

\section{References}

Ahmad, M.A., Alrozi, R., 2011. 2"Removal of malachite green dye from aqueous solution using rambutan peel-based activated carbon: equilibrium, kinetic and thermodynamic studies. Chem. Eng. J. 171 (2), 510-516.

Ahmad, M.A., Ahmad, N., Bello, O.S., 2014. Adsorption kinetic studies for the removal of synthetic dye using durian seed activated carbon. J. Dispersion Sci. Technol. 36 (5), 670-684.

Ahmad, M.A., Afandi, N.S., Adegoke, K.A., Bello, O.S., 2015. Optimization and batch studies on adsorption of malachite green dye using rambutan seed activated carbon. Desalination Water Treat. 57 (45), 21487-21511.

Amit, B., Anastopoulos, I., 2017. Adsorptive removal of bisphenol A (BPA) from aqueous solution: a review. Chemosphere 168, 885-902.

Anastopoulos, C., 2017. What is an endocrine disruptor? Comptes Rendus Biol. 340, 9-10.

Ansari, R., Mohammad-Khah, A., 2009. Activated charcoal: preparation, characterization and applications: a review article. Int. J. Chem. Technol. Res. 1 (4), 859-864.

Baccar, R., Sarrà, M., Bouzid, J., Feki, M., Blánquez, P., 2012. Removal of pharmaceutical compounds by activated carbon prepared from agricultural by-product. Chem. Eng. J. 211, 310-317.

Balarak, D., 2016. Kinetics, isotherm and thermodynamics studies on bisphenol a adsorption using Barley husk. Int. J. Chem. Technol. Res. 9 (5), 681-690.

Bello, O.S., Ahmad, M.A., 2012. Preparation and characterization of activated carbon derived from rubber seed coat" chemistry. Bulg. J. Sci. Educ. 21 (3), 389-395 66.

Bello, O.S., Owojuyigbe, E.S., Babatunde, M.A., Folaranmi, F.E., 2016. Sustainable conversion of agro-wastes into useful adsorbents. Appl. Water Sci. 7 (7), 3561-3571.

Bello, O.S., Lasisi, B.M., Adigun, O.J., Ephraim, V., 2017. Scavenging Rhodamine B dye using seed pod. Chem. Speciat. Bioavailab. 29 (1), 120-134.

Benaddi, H., Legras, D., Rouzaud, J.N., Beguin, F., 1998. Influence of the atmosphere in the chemical activation of wood by phosphoric acid. Carbon 36, 306-309.

Bany-Aiesh, H., Banat, R., Al-Sou'od, V., 2015. Kinetics and adsorption isotherm of Ibuprofen onto Grafted B-CD/Chitosan Polymer. Am. J. Appl. Sci. 12 (12), 917-930.

Boehm, H.P., 1966. Chemical identification of surface groups. Adv. Catal. 16 (179-274), $360-564$.

Chu, K.H., 2002. Removal of copper from aqueous solution by chitosan in prawn shell: adsorption equilibrium and kinetics. J. Hazard Mater. 90, 77-95.

Daifullah, A.A.M., Girgis, B.S.H., Gad, M.H., 2004. A study of the factors affecting the removal of humic acid by activated carbon prepared from biomass materials. Colloids Surf., A: Physiocochem. Eng. Asp. 235, 1-10.

Diao, Y., Walawender, W.P., Fan, L.T., 2002. Activated carbons prepared from phosphoric acid activation of grain sorghum. Bioresour. Technol. 81 (1), 45-52.

Diyanati, R.A., Yousefi, Z., Cherati, J.Y., Balarak, D., 2013. The ability of Azolla and lemna minor biomass for adsorption of phenol from aqueous solutions. J. Mazandaran Univ. Med. Sci. 23 (106), 21-28.

Dos, S.E., Dos, S.J.E., Ribeiro, R.P., Rosa, E.S.A.C., Moreira, A.C., Silva de Sá, M.F., 2007. Absence of circadian salivary cortisol rhythm in women with anorexia nervosa. J. Pediatr. Adolesc. Gynecol. 20 (1), 13-18.

Dubinin, M.M., Radushkevich, L.V., 1947. The equation of the characteristic curve of activated charcoal. Dokl. Akad. Nauk SSSR 55, 327-329.

Dubey, S.P., Dwivedi, A.D., Sillanpää, M., Gopal, K., 2010. Artemisia vulgaris-Derived mesoporous honey comb-shaped activated carbon for ibuprofen adsorption. Chem. Eng. J. 165, 537-544.

Farahani, M., Abdullah, S.R.S., Hosseini, S., et al., 2011. Adsorption-based cationic dyes using the carbon active sugarcane bagasse. Procedia Environ. Sci. 10 (Part A), 203-208.

Fierro, V., Torne-Fernandez, V., Montane, D., Celzard, A., 2005. Study of the decomposition of kraft lignin impregnated with orthophosphoric acid. Thermochim. Acta 433, 142-148.

Freundlich, H.M.F., 1906. Over the adsorption in solution. J. Phys. Chem. 57, 385-470.

Girgis, B.S., El- Hendawy, A.A., 2002. Porosity development in activated carbons obtained from date pits under chemical activation with phosphoric acid. Microporous Mesoporous Mater. 52, 105-117.

Guo, J., Lua, A.C., 2003. Adsorption of sulphur dioxide unto activated carbon prepared from oil- palm shells with and without pre-impregnation. Separ. Purif. Technol. 30, 265-273.

Hanen, G., Laurence, R., Yasushi, S., Nizar, B., Laurent, D., 2017. Adsorption of ibuprofen from aqueous solution on chemically surface-modified activated carbon cloths. Arab.
J. Chem. 10 (2), 3584-3594.

Helfferich, F., 1962. Ion-Exchange. McGraw-Hill Book Co-education, New York.

Ho, Y.S., McKay, G., 1999. Pseudo-second order model for sorption processes. Process Biochem. 34, 451-465.

Karol, Š., Ján, D., Mária, V., 2015. Removal of selected pesticides by nano zero-valent iron. Acta Chim. Slovaca 8 (2), 152-155.

Kot-Wasik, A., Debska, J., Jacek, Namiesnik, 2007. Analytical techniques in studies on the environmental fate of pharmaceuticals and personal -care products. Trac. Trends Anal. Chem. 26, 557-568.

Lagergren, S., Svenska, K., 1898. Zur theorie der sogenannten adsorption gelosterstoffe (On the theory of so- called adsorption of materials) Vetenskaps akademiens. Handlingar 24, 1-39.

Langmuir, Irving, 1918. The adsorption of gases on plane surface of glass, mica and platinum. J. Am. Chem. Soc. 40 (9), 1361-1402.

María, E., Raquel, L., Irene, M., Susana, A., Teresa, S., María, F., Ewa, W., Laura, E., Vicente, V., Javier, C., 2017. Defects of splicing in antithrombin deficiency. Res. Prac. Thromb. Haemost. (2), 216-222.

Miège, C., Choubert, J.M., Ribeiro, L., Eusèbe, M., Coquery, M., 2008. Removal efficiency of pharmaceuticals and personal care products with varying wastewater treatment processes and operating conditions - conception of a database and first results. Water Sci. Technol. 57 (1), 49-56.

Mondal, S., Aikat, K., Halder, G., 2016. Biosorptive uptake of ibuprofen by chemically modified Parthenium hysterophorus derived biochar: equilibrium, kinetics, thermodynamics and modeling. Ecol. Eng. 92, 158-172.

Natalia, E., Eich-Höchli, D., Dey, M., Gmel, G., Studer, J., Mohler-Kuo, M., 2014. Prevalence and associated factors for adult attention deficit hyperactivity disorder in young Swiss men. PLoS One 20 (9), 2 e89298.

Ojedokun, A.T., Bello, O.S., 2017. Kinetic modeling of liquid phase adsorption of Congo red dye using guava leaf-based activated carbon. Appl. Water Sci. 7 (4), 1965-1977.

Olakunle, M.O., Inyinbor, A.A., Dada, A.O., Bello, O.S., 2017. Combating dye pollution using cocoa pod husks: a sustainable approach. Int. J. Sustain. Eng. 11 (1), 4-15.

Önal, A.E., 2015. A lecture to explain endocrine disrupting chemicals to the second class students of a medical faculty. Procedia - Soc. Behav. Sci. 174, 959-962.

Qu, Y., 2009. Equilibrium and kinetics study on the adsorption of perfluorooctanoic acid from aqueous solution onto powdered activated carbon. J. Hazard Mater. 169 (1-3), $146-152$.

Russel, W.B., Saville, D.A., Schowalter, W.R., 1989. Colloidal Dispersions, vol 525. University Press, Cambridge, pp. 250.

Sadmani, A.H.M.A., Andrews, R.C., Bagley, D.M., 2014. Rejection of pharmaceutically active and endocrine disrupting compounds by nanofiltration as a function of source water humic substances. J. Water Process Eng. 2, 63-70.

Santos, J., Aparicio, I., Alonso, E., 2007. Occurrence and risk assessment of pharmaceutically active compounds in wastewater treatment plants. A case study: seville city (Spain). Environ. Int. 33, 596-601.

Sui, Q., Huang, J., Liu, Y., Chang, X., Ji, G., Deng, S., Xie, T., Yu, G., 2011. Rapid removal of biphenyl a on highly ordered mesoporous carbon. JES (J. Environ. Sci.) 23, $172-182$.

Tadros, Th, 1998. Polymers in Colloid Systems: Adsorption, Stability and Flow. Elsevier, Amsterdam 1998.

Tan, I.A.W., 2008. Enhancement of basic dye adsorption uptake from aqueous solutions using chemically modified oil palm shell activated carbon. Colloid. Surf. Physicochem. Eng. Asp. 318 (1-3), 88-96.

Temkin, M.J., Pyzhev, V., 1940. Kinetics of ammonia synthesis on promoted iron catalysts. Acta Physiochim. URSS 12, 217-222.

Venersson, T., Bonelli, P.R., Cerella, E.G., Cukierman, A.L., 2002. Arundo donax cane as a precursor for activated carbons preparation by phosphoric acid activation. Bioresour. Technol. 83, 95-104.

Weber Jr., W.J., Morris, J.C., 1963. Kinetics of adsorption of carbon from solutions. J. Sanit. Eng. Div. Am. Soc. Civ. Eng. 89, 31-59.

Zacharewski, T.R., Meek, M.D., Clemons, J.H., Wu, Z.F., Fielden, M.R., Matthews, J.B., 1998. Examination of the in vitro and in vivo estrogenic activities of eight commercial phthalate esters. Toxicol. Sci. 46 (2), 282-293.

Zazouli, M.A., Yazdani, J., Balarak, D., Ebrahimi, M., Mahdavi, Y., 2013. Removal acid blue 113 from aqueous solution by canola. J. Mazandaran Univ. Med. Sci. 23 (2), $73-81$.

Zazouli, M.A., Pouneh, E., Maryam, B.A., 2014. Study of Cd (II) and Cr (VI) biosorption by mesocarps of orange and sour orange from aqueous solutions. Environ. Eng. Manag. J. 13 (2), 345-351. 